Article

\title{
Facial Expressions of Visitors in Forests along the Urbanization Gradient: What Can We Learn from Selfies on Social Networking Services?
}

\author{
Hongxu Wei ${ }^{1}{ }^{D}$, Richard J. Hauer ${ }^{2}$, Xin Chen ${ }^{1}$ and Xingyuan He ${ }^{1,3, *}$ \\ 1 Northeast Institute of Geography and Agricultural Ecology, Chinese Academy of Sciences, \\ Changchun 130102, China; weihongxu@iga.ac.cn (H.W.); chenxin_iga@sina.com (X.C.) \\ 2 College of Natural Resources, University of Wisconsin-Stevens Point, 800 Reserve St., Stevens Point, \\ WI 54481, USA; rhauer@uwsp.edu \\ 3 University of Chinese Academy of Sciences, Beijing 100049, China \\ * Correspondence: hexingyuan@iga.ac.cn; Tel.: +86-431-8554-2277
}

Received: 26 October 2019; Accepted: 18 November 2019; Published: 20 November 2019

check for updates

\begin{abstract}
People's satisfaction towards the experience in forests is one of most important feedbacks that forest park managers need to meet positive visitors' experiences. Although the drawbacks of questionnaire methodology are obvious for data collection from self-reported scores at the landscape scale, few alternative methods have been proposed. In this study, nine urban forest parks along the urbanization gradients in three capital cities of Northeast China were targeted to investigate their visitors' selfies from social networking services (SNS) by assessing facial expressions. A total of 935 photos with location records were obtained from the SNS platform of Sina Micro-Blog in a social hot-event of 'Golden Week Holidays of National Day of China' of 2017. Images were recognized by FireFace software to assess scores of neutral, happy, sad, angry, surprised, scared, disgusted, and contempt expressions. Data were ranked in descending order and analyzed by Friedman's test, correlation analysis, and Poisson regression. Visitors in downtown-forests showed fewer negative expressions at the most northern city than at the southern most one. The negative expressions tended to be alleviated with the increasing distance of forest parks from downtown. However, when the distance reached over $10 \mathrm{~km}$ no geographical effect was found. Female visitors showed positive emotional expressions to urban forests while male visitors showed no response. In conclusion, using data from SNS, this study found an experience in forest park less than $10 \mathrm{~km}$ from the downtown of a northern city resulted in female visitors showing the most positive expressions.
\end{abstract}

Keywords: ecosystem services; forest bathing; urbanization; city well-being; anxiety alleviation; stress relief

\section{Introduction}

Forests account for one of the largest green spaces in a city's landscape. The socioeconomic functions of forests have drawn more and more attention of contributions to restoration, leisure, recreation and aesthetics [1]. Forests can supply services to alleviate psychological depression and reduce mental stress for visitors, which has been taken as an important trait of modern forested landscapes [2-9]. This effect was termed as "forest bathing", i.e., spending some time for walking, viewing, and breathing in the forest atmosphere to gain restoration $[2,10,11]$. The forest bathing effect was shown to induce more promotion of well-being when compared to the experience in the built-up urban environment [4,7-9,11-20]. As urbanization is accelerating [21], large-scale forest management is more important to generate the forest bathing effect not only from rural and suburban regions, but also in near-center forested lands. 
People's perception towards the forest environment may vary from one place to another depending on the geographical proximity to urbanized lands [22]. Therefore, the theoretical magnitude of mental restoration that can be perceived through a forest experience at least partly depends on the location of the receiver along the urban-rural gradient. Currently, Asian studies have dominated the field of forest bathing effect [9]. Most of these were conducted as pilot investigations in forests at less urbanized areas [18,23], but less is known about the functional service of forests in the city center. Recently studies from Poland [24,25], United States [19], and Sweden [9] started to focus on the restorative effect of forests near downtown. However, these studies were scattered over a large distance, which makes it very difficult to draw solid conclusions about the function of the regional forest community along the urbanization gradient. Assessing the emotional response of visitors to urban forests at different urbanized locations can result in better clarification of the effect of urban forests on well-being.

Due to greater population density in the central urban area, forested lands near the city center were considered a scarce resource and perceived with great non-material value as cultural ecosystem services $[26,27]$. They were also perceived by urban dwellers as a way to promote citizens' well-being and quality of life by providing aesthetic and recreational services [27-29]. In contrast, forests in less urbanized areas were mainly needed for material outcomes by local people [26,28,29]. Data from these studies were mainly collected through questionnaire-based surveys or interviews $[9,27,30]$. Self-reported scores are the main data source that were used to evaluate visitors' perception to the forest experience $[4,5,9,14,18,23,31]$. The profile mood state (POMS) questionnaire is the most widely used approach to evaluate forest-visitors' perception. Participants were usually recruited in a number between 10 and 20, and few had the population over a 20-individual population [5,18,23]. This was because to finish POMS questionnaires requires additional time for recruiting willing participants to complete a survey $[4,14]$. For example, Stigsdotter et al. recruited 41 female university students and investigated their self-evaluation, which required a time as long as six months [9]. The lack of a large number of samples likely brings about technical bias of imprecise reflection of the potential population. This has greatly limited the management strategy of forests to supply high-quality services to the public, but the sole dependence on the questionnaire methodology will increase the budget to a considerable extent if a large number of participants is essentially needed.

Social networking services (SNS) have become a common communication approach for modern-age people. Frequent users are fond of reporting their latest experience by posting personal facial images to the SNS platform [32,33]. As a result, millions of facial expression images are being uploaded to the internet through the SNS pathway every minute all over the world [34,35]. The rapid increase in mobile devices and number of SNS applications contribute to an enlarged pool of personal photos with location information. This inspires the idea to reveal spatial variation of visitors' perception in forested landscapes. This can be achieved by extracting information about emotional perception from facial expressions in photos by visitors. When visitors were walking in an urban forest, they tended to take a photo and upload it to the SNS. Therefore, the large-scale evaluation of visitors' emotions among different urban forests at the same time can be evaluated.

Face-reading is a novel technique that analyzes visual recordings of faces through a software algorithm that was generated by training the model using big-data of intended-emotion expressions. Current technology can achieve accuracy of facial analysis in as high as $87 \%$ of the perceived emotion [36]. This can fully support the analysis of facial expressions with location information from SNS sufficiently. At the worldwide scale, platforms such as Facebook and Twitter are famous SNS media that allow billions of photos to be uploaded and open to the public. In China, the largest SNS for mobile devices is WeChat (or Weixin in Chinese) (Tencent Inc., Shenzhen, China), which has more than 938 million monthly active user accounts [37]. WeChat has a privacy policy for images in the self-controlled-users' photo frames, which can only be browsed by authorized friends. Instead, the Sina Micro-Blog software (or Weibo in Chinese) (Sina Inc., Beijing, China) is an open-access SNS platform where all facial images are free for public if no special limit is established by the uploader. Sina Micro-Blog had nearly 380 million active monthly user counts and over 160 million active daily user counts. Users can take and 
upload selfies using the Sina Micro-Blog application in mobile devices, which also enables users to upload the geographical information about instant check-in data of the location. The Sina Micro-Blog platform has been used as a modern approach to study human behavior in urban areas. Both can be downloaded and analyzed by personal computers [38,39]. Therefore, Sina Micro-Blog is an optimum platform that supplies photos for analysis of people's perception to the location of forested lands.

The objective of this study was to emotionally assess the facial expression responses of visitors to urban forests with varied public areas in different regions and urbanization levels. We tested the scores of eight facial expressions (neutral, happiness, sadness, anger, surprise, disgust, scare, and contempt) for their relationship to urban forest structure. The expressions of happiness and sadness were central to the analysis since they can reflect visitors' emotion more precisely than other expressions. We hypothesized that more positive emotional expressions would be found on faces of visitors to the forest parks located in remote-rural area than in downtown. Our study provides a useful reference for evaluating the effect of urban forests at different locations on the psychological state of visitors. Finally, the study provides a rapid method for future urban planning studies to evaluate the effect of urban-forest-experience on a persons' perception of well-being.

\section{Materials and Methods}

\subsection{Study Area}

The study was conducted in the Northeast China capital cities of Changchun, Harbin, and Shenyang that are located in Jilin, Heilongjiang, and Liaoning Provinces, respectively (Figure 1). The locations were chosen due to their varied forest types and changes in urban forest structure over the past four decades. Changchun city $\left(43^{\circ} 46^{\prime}-43^{\circ} 58^{\prime} \mathrm{N}, 125^{\circ} 09^{\prime}-125^{\circ} 48^{\prime} \mathrm{E}\right)$ is in the hinterland of the Northeast Plain with a total population of 3.6 million (2010 data) inhabiting an urban area of $285 \mathrm{~km}^{2}$. Changchun has become famous locally as "the Forest City" due to the $45 \%$ tree canopy cover. In Changchun, even though rapid increases in urbanization have occurred since 1979, the urban forest patch density and tree density have increased by $162 \%$ and $37 \%$, respectively after three decades of active urban tree planting. Harbin $\left(44^{\circ} 04^{\prime}-46^{\circ} 40^{\prime} \mathrm{N}, 125^{\circ} 42^{\prime}-130^{\circ} 10^{\prime} \mathrm{E}\right)$ was founded in 1896 and has been regarded as a "Garden City". The urbanization of Harbin started in 1978 and during such time the urban forest structure has increased through introductions of nine families and 17 genera of forest woody species due to the intensive afforestation construction of the new urbanized regions. In Harbin, the landscape prior to the rise in newly urbanized regions was typically unforested and afforestation increased through a requirement of more greening by newly settled residents in the 53.10 thousand $\mathrm{km}^{2}$ region. Shenyang $\left(41^{\circ} 48^{\prime}-43^{\circ} 22^{\prime} \mathrm{N}, 123^{\circ} 25^{\prime}-130^{\circ} 07^{\prime} \mathrm{E}\right)$ has an area of 12.95 thousand $\mathrm{km}^{2}$ with a population of 8.3 million people in 2015. Shenyang belongs to the North China flora area and occurs between the Changbai and Mongolia flora zones [40]. 


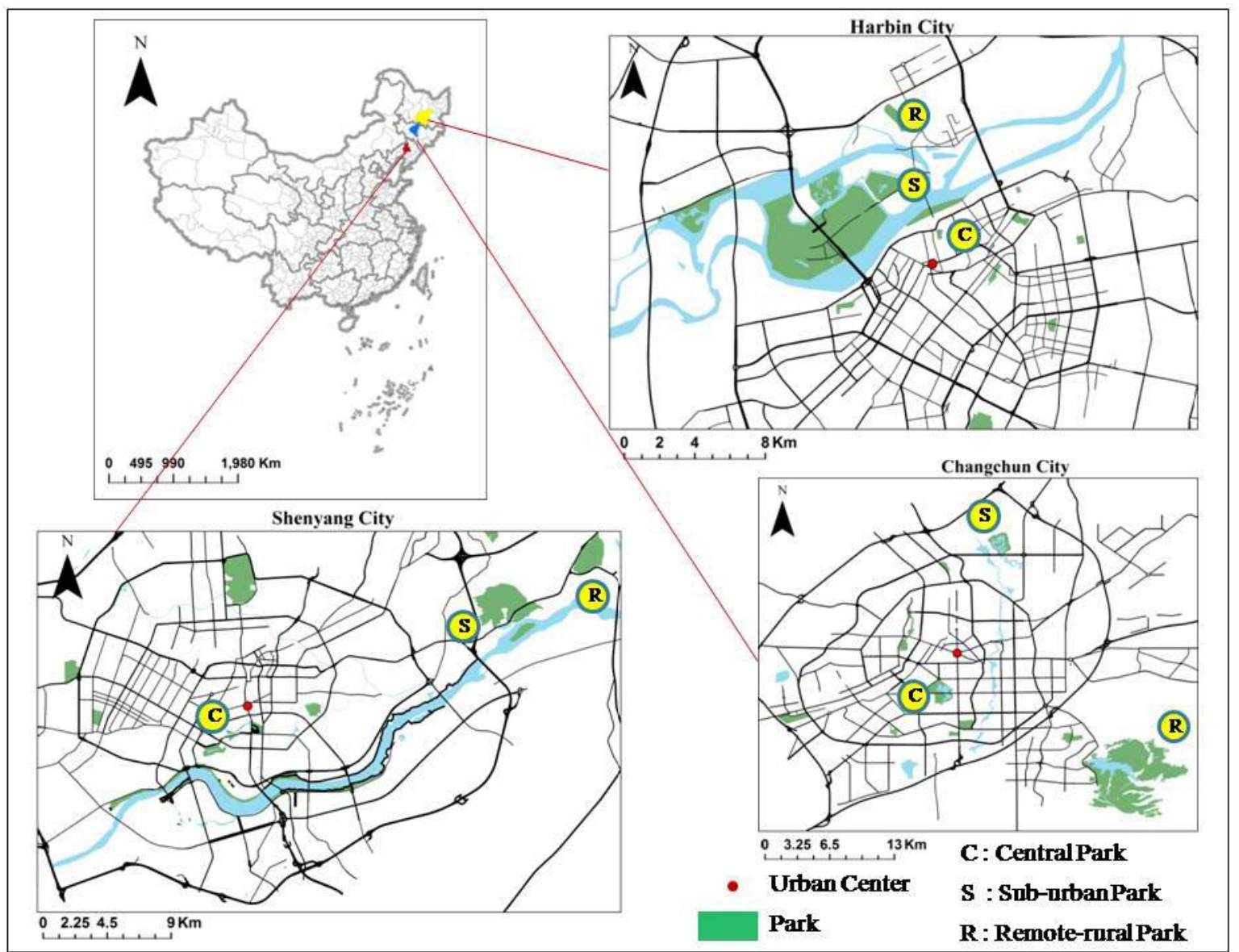

Figure 1. The distribution of urban forest parks locating at the city-center, suburban, and remote-rural areas of cities of Changchun, Harbin, and Shenyang in Northeast China.

\subsection{Urban Forest Park Selection}

We selected three urban forest parks located within each city. Forest parks ranged from a downtown area that was fully urbanized to a suburban and then remote-rural areas furthest away from the downtown. The parks of different urbanization fell within a ring-road circle pattern common in China cities. The mostly urbanized area near downtown resulted in a typical urbanization pattern of a circle with the downtown at the center and increasing boundaries of ring-roads. Selection of sites in the downtown area for each of the three cities used methods adapted from Stigsdotter et al. [9]. In a given city, the downtown represents the typical architectural style used locally and the historical qualities unique to each area. All forest parks within each ring-road circle were candidate study sites and those with the most facial images were then selected as study sites. The check-in data from Sina Micro-Blog software was used to rank each candidate site, with the largest visiting populations used as a criterion to select the three parks for each city. Parks in each city were selected by distance to downtown to provide a gradient of urbanization. The park name, city, and distance of parks from the downtown for each selected forest park (Table 1) and their distributions (Figure 1) were recorded. 
Table 1. Details about name, area, and location of urban forest parks and number of two genders of visitors therein in cities of Changchun, Harbin, and Shenyang in Northeast China.

\begin{tabular}{|c|c|c|c|c|c|c|c|}
\hline Downtown & Forest Park & Area (ha) & $\begin{array}{c}\text { Distance from } \\
\text { Downtown }(\mathbf{k m})\end{array}$ & $\begin{array}{c}\text { Park } \\
\text { Location }\end{array}$ & $\begin{array}{c}\text { Male } \\
\text { Number }\end{array}$ & $\begin{array}{l}\text { Female } \\
\text { Number }\end{array}$ & $\begin{array}{c}\text { Total } \\
\text { Number }\end{array}$ \\
\hline \multicolumn{8}{|c|}{-Changchun- } \\
\hline \multirow{4}{*}{ People's square } & Nanhu & 222 & 3.5 & $C^{1}$ & 34 & 95 & 129 \\
\hline & Beihu & 205 & 10.5 & $S^{2}$ & 3 & 17 & 20 \\
\hline & Jingyuetan & 2052 & 15.5 & $\mathrm{R}^{3}$ & 37 & 90 & 127 \\
\hline & & & arbin- & & & & \\
\hline \multirow{3}{*}{$\begin{array}{l}\text { Harbin Railway } \\
\text { Station }\end{array}$} & Zhaolin & 7 & 1.8 & $\mathrm{C}$ & 10 & 26 & 36 \\
\hline & Sun-isle & 246 & 4.5 & $\mathrm{~S}$ & 26 & 101 & 127 \\
\hline & $\begin{array}{l}\text { Northeast Tigers } \\
\text { Garden }\end{array}$ & 105 & 7 & $\mathrm{R}$ & 27 & 73 & 100 \\
\hline \multicolumn{8}{|c|}{ —Shenyang- } \\
\hline \multirow{4}{*}{$\begin{array}{l}\text { The Youth Str. } \\
\text { Subway Station }\end{array}$} & Nanhu & 82 & 2.5 & C & 15 & 77 & 92 \\
\hline & Dongling & 833 & 14 & $\mathrm{~s}$ & 37 & 49 & 86 \\
\hline & Int. Hort. Exp. & 369 & 19 & $\mathrm{R}$ & 54 & 164 & 218 \\
\hline & & & \multicolumn{2}{|c|}{ Total number } & 243 & 692 & 935 \\
\hline
\end{tabular}

Note: ${ }^{1} \mathrm{C}$, city-center; ${ }^{2} \mathrm{~S}$, suburban; ${ }^{3} \mathrm{R}$, rural.

\subsection{Facial Image Data}

Facial images from user-supplied selfies were first screened on-line for a two-week period from 24:00 of 30 September to 24:00 of 7 October 2017. The selfies within the screening standard described below were downloaded for expression analysis. This time period was chosen because it overlapped a social hot-event of a short holiday to celebrate National Day of China, which resulted in a large increase of active users in Sina Micro-Blog above typical daily image uploads [41]. This time period was also chosen to study check-in data of urban residents in Sina Micro-Blog [39]. Images containing the frontal view of an intact face were analyzed because this kind of image can best facilitate the computer recognition by the software [42]. Sometimes a head-pose in our collected images that resulted in non-frontal faces were still screened as candidates for expression analysis if all sensory organs were shown clearly at or near symmetry. Although facial images with a range of head poses can be analyzed for emotional expression, the non-frontal-face images need to be screened to reduce unfavorable characteristics [42,43]. Therefore, this kind of image was excluded from our first screening. Respondents wearing sunglasses or light-reflecting glasses were excluded because their image cannot be analyzed for expressions around their eyes. We found that nearly $100 \%$ of the images were selfies and the few non-selfies were excluded from the study. The faces with heavy makeup or modification (less than 2\%) failed to pass the screening as they may impact the precision of expression analysis. A total of 1139 facial images passed the first-round screening and 935 of them met study requirements and were downloaded for further analysis. The gender proportion and geographical distribution of these images are shown in Table 1.

\subsection{Experimental Design}

This study was structured by a split-block design on eight facial-expression scores within three cities (Changchun, Harbin, and Shenyang) as the main block and geographical locations (fully urbanized, suburban, and remote-rural areas) as the sub-block. No exact replicates were presented because the number of available expression data depended on the real-time number of selfies. Each facial-expression score of every selfie can be taken as a replicate for the combined city-location independent variable for the study of this emotional expression. We found that sometimes one person took more than one selfie and uploaded all of them up to the service of Sina Micro-Blog. This resulted an issue of different expressions from a same face. However, we eliminated this effect on results by manually screening these kinds of photos. 


\subsection{Analytical Method}

The FireFace (ver. III frontier edition) software was used in this study to recognize selfies and access eight basic emotional expressions: neutral, happy, sad, angry, surprised, scared, disgusted, and contempt. The magnitude of each expression on one face was valued by the frequency given by the software, which has been trained to recognize at high precision. We focused on extreme expressions of "happy" and "sad" and used scores of these two expressions for further calculation because they can reflect the emotion more precisely than others $[36,44]$. The positive response index (PRI) was employed as a scoring metric and is defined as the difference between scores for happy and sad emotions to evaluate the net positive level of favorable reaction of visitors in the urban forests [36].

SAS (ver. 9.4 64-bit, SAS Institute, Cary, NC, USA) software was used for data analysis. Data were checked for a normal distribution and found to be non-normally distributed. Therefore, both facial-expression scores and PRI values were ranked to be distribution-free for the analysis by the non-parametric method [45]. Our data were ranked in a descending order to meet the Poisson distribution. Ranked data were tested by Friedman's chi-square test to detect the probability of different row-means in data tables stratified by variations from cities, urban-forest park locations, and their interactions. When a significant effect was found, data were arranged and compared by the Wilcoxon rank-sum test [46,47]. Bonferroni adjustment was employed to test for significance at the 0.05 level [48]. Subsequently, the relationship between the forest-distance to the city center and eight facial-expression scores were analyzed by the Pearson correlation. Finally, a Poisson regression model was used to analyze the effects of multiple geographic and demographic factors on PRI [36]. The Poisson regression was conducted to detect the PRI response to multiple independent variables of city-variation, park-location, to-center distance, park area, and visitors' gender (open data on Sina Micro-Blog). A Poisson model needs an offset variable to normalize the fitted means by specifying a constant value. The logarithmic value of the time spent level on Sina Micro Blog for photo-used visitors was used as the offset variable since it was not used as an explanatory variable.

\section{Results}

\subsection{Demographical Analysis}

Generally, more women than men in urban forest parks took selfies (Table 1). The number of female visitors $(n=692)$ was 202, 200, and 290 in Changchun, Harbin, and Shenyang, respectively; while the number male $(n=243)$ visitors therein were 74,63 , and 106 , respectively. More selfies were collected and passed the screening standard from visitors to the forest parks in the remote-rural area in Harbin and Shenyang. In Changchun, very few images $(n=20)$ were uploaded and met screening standards in the suburban area.

\subsection{Emotional Expressions at Different Urbanization-Leveled Regions in Three Cities}

No interactive effects of city variation and urban-park location were detected for any of the eight facial expressions (Table 2). A significant response was found for ranked scores of neutral, angry, and disgusted facial expressions among different cities and the ranked score for disgusted expression among different forest-park locations across cities (Table 2). Because our data were ranked in a descending order, the comparison revealed the opposite trend among means. Urban-forest visitors showed a $12 \%$ higher score of neutral expression in Shenyang than in Changchun (Exact test, two-sided $\mathrm{Pr} \geq \mid \mathrm{S}$-mean $\mid$ $=0.0065$ ) (Figure 2a), but the angry-expression score in these two cities were both higher than that in Harbin by about $11 \%(\operatorname{Pr} \geq \mid \mathrm{S}$-mean $\mid=0.0129)$ (Figure $2 \mathrm{~b})$. Visitors in Changchun showed a higher disgusted facial-expression score than in Shenyang and Harbin $(\operatorname{Pr} \geq|\mathrm{S}-\mathrm{mean}|=0.0077$ and 0.0158 , respectively) (Figure 2c). Visitors generally showed higher disgusted facial-expression scores in forest parks at city center than in rural area $(\operatorname{Pr} \geq \mid \mathrm{S}$-mean $\mid=0.0061)$ (Figure $2 \mathrm{~d}$ ). 
Table 2. Summary statistics by Friedman's chi-square test on ranked scores for neutral, happy, sad, angry, surprised, disgusted, scared, and contemptuous facial expressions from visitors stratified by variants of different cities (City), park locations (Location), and their interaction (City $\times$ Location).

\begin{tabular}{cccccccc}
\hline Facial Expression & $d f$ & \multicolumn{3}{c}{ Cochran-Mantel-Haenszel Statistics (Based on Ranked Scores) } \\
\hline & & \multicolumn{2}{c}{ City } & \multicolumn{2}{c}{ Location } & \multicolumn{2}{c}{ City $\times$ Location } \\
\cline { 2 - 8 } & & Value & $\boldsymbol{p}$ & Value & $\boldsymbol{p}$ & Value & $\boldsymbol{p}$ \\
\hline Neutral & 2 & $\mathbf{8 . 9 4 5 0}$ & $\mathbf{0 . 0 1 1 4}$ & 3.8304 & 0.1473 & 3.4999 & 0.1738 \\
Happy & 2 & 2.2952 & 0.3174 & 0.8141 & 0.6656 & 2.1851 & 0.3354 \\
Sad & 2 & 3.0250 & 0.2204 & 2.3478 & 0.3092 & 0.4912 & 0.7822 \\
Angry & 2 & $\mathbf{1 0 . 1 2 6 0}$ & $\mathbf{0 . 0 0 6 3}$ & 4.2485 & 0.1195 & 0.6112 & 0.7367 \\
Surprised & 2 & 0.4531 & 0.7973 & 2.9156 & 0.2327 & 2.8658 & 0.2386 \\
Disgusted & 2 & $\mathbf{8 . 6 8 2 2}$ & $\mathbf{0 . 0 1 3 0}$ & $\mathbf{8 . 3 4 0 3}$ & $\mathbf{0 . 0 1 5 5}$ & 5.7567 & 0.0562 \\
Scared & 2 & 3.7724 & 0.1517 & 6.6291 & 0.0364 & 6.4153 & 0.0405 \\
Contempt & 2 & 1.0092 & 0.6037 & 2.1110 & 0.3480 & 1.6812 & 0.4314 \\
\hline
\end{tabular}

Note: ${ }^{1}$ Values in bold-font indicate significant effect at the 0.0167 level (adjusted by the Bonferroni method from 0.05 ).
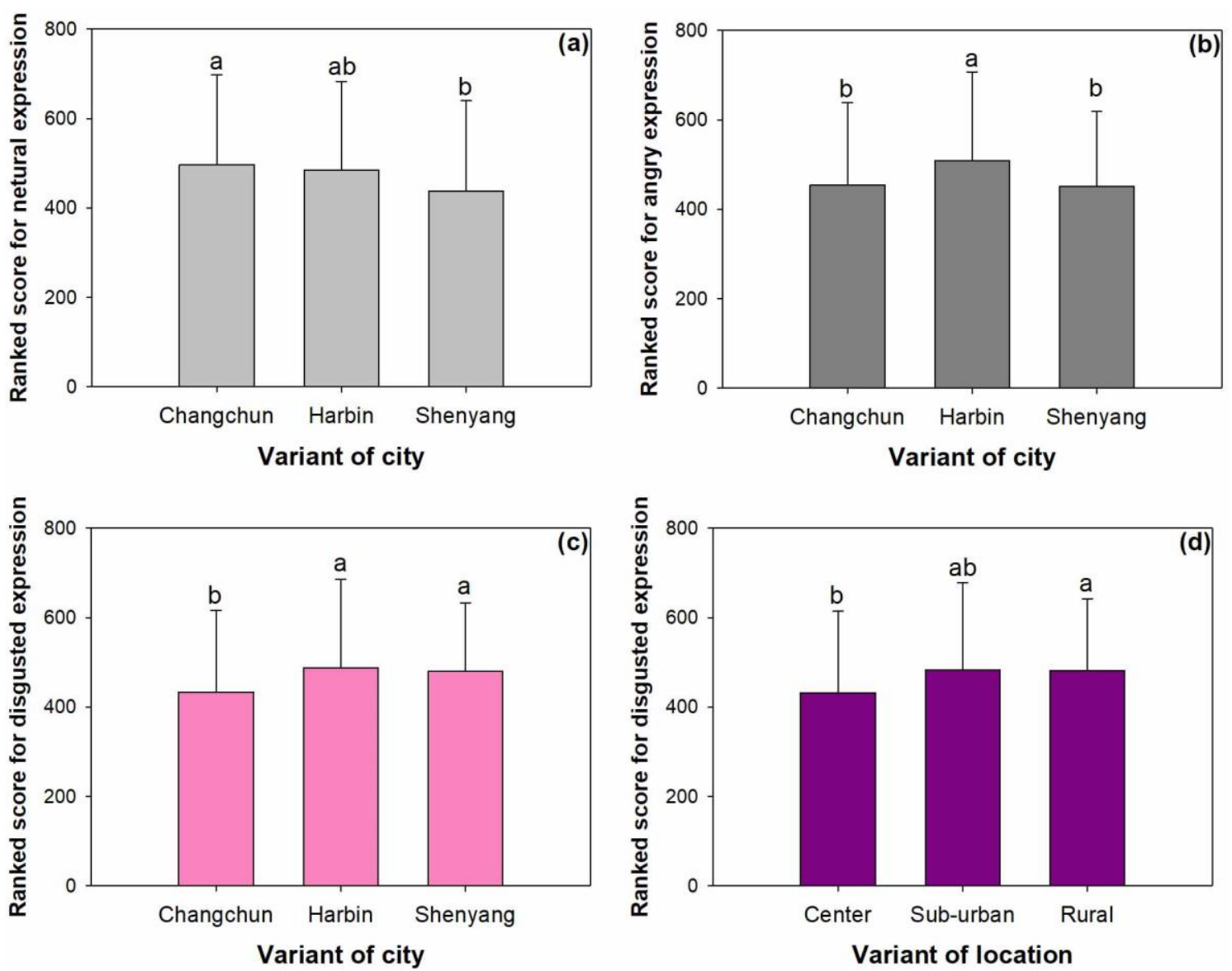

Figure 2. Ranked scores for neutral (a), angry (b), and disgusted (c) facial expressions among different cities and those for disgusted facial expression among different forest-park locations across cities (d). Different letters indicate significant difference of ranked scores between any couple of the three comparisons according to Wilcoxon rank sum test at the 0.0167 level adjusted from the Bonferroni method. Error bars above columns indicate standard errors. 


\subsection{Relationship between Distance from Downtown and Emotional Scores in Each City}

Because our data were ranked in descending order, the regression between distance of the urban forest parks to downtown and visitors' facial-expression scores revealed an adverse relationship. In Changchun, visitors tended to show less angry expressions as distance from the city center increased (Table 3). In Harbin, visitors tended to show higher scared scores in the rural area than in the city center. In Shenyang, as the distance of forest parks to the city center increased, visitors therein tended to show a lower score of happy expression. They also showed lower scores of sad and angry expressions with higher determination coefficients.

Table 3. Coefficients from Pearson correlation between the distance from downtown for urban forest parks and ranked scores of eight facial expressions of visitors therein in Cities of Changchun, Harbin, and Shenyang at Northeast China.

\begin{tabular}{|c|c|c|c|c|c|c|c|c|c|}
\hline Independent & Coefficient & Neutral & Happy & Sad & Angry & Surprised & Disgusted & Scared & Contempt \\
\hline \multirow{9}{*}{$\begin{array}{l}\text { Distance } \\
\text { from } \\
\text { downtown }\end{array}$} & \multicolumn{9}{|c|}{ Changchun $(n=276)$} \\
\hline & $R$ & 0.0258 & -0.0652 & 0.09854 & $0.1740^{1}$ & -0.0095 & 0.0452 & 0.0191 & 0.0557 \\
\hline & $P$ & 0.6696 & 0.2801 & 0.1023 & 0.0037 & 0.8746 & 0.455 & 0.7521 & 0.3564 \\
\hline & \multicolumn{9}{|c|}{ Harbin $(n=263)$} \\
\hline & $R$ & 0.0655 & -0.0694 & -0.0734 & -0.0502 & 0.0129 & -0.0881 & -0.1286 & 0.0067 \\
\hline & $P$ & 0.2896 & 0.2615 & 0.2348 & 0.4163 & 0.8343 & 0.1532 & 0.0368 & 0.9144 \\
\hline & \multicolumn{9}{|c|}{ Shenyang $(n=396)$} \\
\hline & $R$ & -0.0447 & 0.1106 & 0.1351 & 0.1635 & 0.0222 & 0.0766 & 0.1051 & 0.0138 \\
\hline & $P$ & 0.3759 & 0.0282 & 0.0072 & 0.0011 & 0.6599 & 0.1293 & 0.0370 & 0.7850 \\
\hline
\end{tabular}

Note: ${ }^{1}$ Values in bold-font indicate significant correlation.

\subsection{Geographic and Demographic Effects on PRI}

City variation and urban-forest-park location factors did not have any interactive effect on ranked PRI (the Cochran-Mantel-Haenszel statistics, $p=0.3848$ ). In addition, neither the variation of city nor that of location had significant effect on ranked PRI scores ( $p=0.3083$ and $p=0.7767$, respectively).

Poisson modeling indicated that the park area was not correlated with PRI; hence, the park area was excluded from the Poisson regression analysis. The Chi-square test indicated a significant effect from the intercept of the whole model, indicating that the Poisson model can describe all factors of city variation, urbanization, distance from downtown, and visitors' gender well (Table 4). Estimates of both Changchun and Harbin cities were negative on ranked PRI, indicating positive contributions of descending ranks of data from these two cities to the generation of PRI. Among three urbanization levels, forests in both downtown and rural areas had negative effects on ranked PRI (Table 4). The magnitude of the estimated effect of forest distance to downtown on PRI tended to fluctuate to a distance to approximately $10 \mathrm{~km}$. Urban forest parks located $10 \mathrm{~km}$ or further away from the downtown had no significant contribution to PRI. Facial expressions of female visitors contributed to a positive effect on PRI, while male visitors' expressional scores had no effect. Among all variables, gender contributed to the highest increase on PRI, followed by the contribution from Harbin city. 
Table 4. Analysis of parameter estimates of effects from independent variables of city difference, urbanization level, distance to the city center, and visitors' gender on the dependent of descending ranks of positive response index (PRI) given by the Poisson regression.

\begin{tabular}{|c|c|c|c|c|c|c|c|c|}
\hline \multicolumn{2}{|c|}{ Independent Variables } & \multirow{2}{*}{$\frac{\mathrm{DF}^{1}}{1}$} & \multirow{2}{*}{$\begin{array}{c}\text { Estimate } \\
3.3533^{3}\end{array}$} & \multirow{2}{*}{$\frac{\mathrm{SE}^{2}}{0.0049}$} & \multicolumn{2}{|c|}{ Confidence Limits } & \multirow{2}{*}{$\begin{array}{c}\text { Chi-Square } \\
465,306\end{array}$} & \multirow{2}{*}{$\begin{array}{c}P r>C h i S q \\
<0.0001\end{array}$} \\
\hline PRI-Intercept & & & & & 3.3436 & 3.3629 & & \\
\hline City & Changchun & 1 & -0.1374 & 0.0053 & -0.1477 & -0.1270 & 677.12 & $<0.0001$ \\
\hline City & Harbin & 1 & -0.2717 & 0.0057 & -0.2829 & -0.2604 & 2240.50 & $<0.0001$ \\
\hline City & Shenyang & 0 & 0.0000 & 0.0000 & 0.0000 & 0.0000 & 0.0000 & \\
\hline Urbanization & $C^{4}$ & 1 & 0.2346 & 0.0082 & 0.2186 & 0.2506 & 822.65 & $<0.0001$ \\
\hline Urbanization & $\mathrm{S}^{5}$ & 0 & 0.0000 & 0.0000 & 0.0000 & 0.0000 & 0.0000 & \\
\hline Urbanization & $\mathbf{R}^{6}$ & 1 & 0.1064 & 0.0057 & 0.0945 & 0.1175 & 353.99 & $<0.0001$ \\
\hline Distance & 1.8 & 1 & 0.0430 & 0.0108 & 0.0219 & 0.0641 & 15.94 & $<0.0001$ \\
\hline Distance & 2.5 & 1 & -0.2272 & 0.0084 & -0.2437 & -0.2106 & 725.75 & $<0.0001$ \\
\hline Distance & 3.5 & 0 & 0.0000 & 0.0000 & 0.0000 & 0.0000 & 0.0000 & \\
\hline Distance & 4.5 & 1 & 0.3453 & 0.0086 & 0.3285 & 0.3621 & 1623.83 & $<0.0001$ \\
\hline Distance & 7 & 0 & 0.0000 & 0.0000 & 0.0000 & 0.0000 & 0.0000 & . \\
\hline Distance & 10.5 & 1 & -0.2292 & 0.0144 & -0.2573 & -0.2010 & 254.04 & $<0.0001$ \\
\hline Distance & 14 & 0 & 0.0000 & 0.0000 & 0.0000 & 0.0000 & 0.0000 & . \\
\hline Distance & 15.5 & 0 & 0.0000 & 0.0000 & 0.0000 & 0.0000 & 0.0000 & . \\
\hline Distance & 19 & 0 & 0.0000 & 0.0000 & 0.0000 & 0.0000 & 0.0000 & . \\
\hline Gender & $0^{7}$ & 1 & -0.3580 & 0.0033 & -0.3645 & -0.3515 & $11,735.4$ & $<0.0001$ \\
\hline Gender & 1 & 0 & 0 & 0 & 0 & 0 & . & . \\
\hline Scale & & 0 & 1.0000 & 0.0000 & 1.0000 & 1.0000 & & \\
\hline
\end{tabular}

Note: ${ }^{1} \mathrm{DF}$, degree of freedom. ${ }^{2} \mathrm{SE}$, standard error. ${ }^{3}$ Values in bold-font indicate significant contributions. ${ }^{4} \mathrm{C}$, city center. ${ }^{5} \mathrm{~S}$, suburban. ${ }^{6} \mathrm{R}$, rural. ${ }^{7}$ Gender 0 as female and 1 as male.

\section{Discussion}

\subsection{The Difference of Facial-Expression Scores among Cities}

In our study, the Poisson regression indicated the positive contributions of data collected from Harbin and Changchun cities to the PRI. Data from Harbin further had a more positive contribution than Changchun. However, emotional scores of visitors in Shenyang had no effect on PRI. Harbin occurs at the northernmost side of our study area and our results suggest that visitors in urban forests of a northern city tended to show more positive emotion on their faces than those in forests at a southern city. More specifically, visitors to the urban forests showed the lowest score of angry expression in Harbin among the three cities, while they also showed a lower score of disgusted expression in Harbin than in Changchun.

Environmental factors can also affect results of this and similar studies. The temperature variation of the three cities drove the different responses of visitors' facial expressions in urban forests. During 1-7 October 2017, the daily temperature in Harbin ranged between $0^{\circ} \mathrm{C}$ and $21^{\circ} \mathrm{C}$ and in Shenyang ranged between $0{ }^{\circ} \mathrm{C}$ and $23^{\circ} \mathrm{C}$. We consider the lower fall temperature in Harbin depressed the negative emotions on visitors' faces. Some studies have revealed the 'cooling effect' of urban forest on visitors' mental-state. For example, data from 14 comparisons of forests and urban settings across Japan revealed that the cool temperature in the forest was associated with the relaxation from a tense mood [4]. Lower fall temperatures were also associated with higher blood pressure in a birch forest of an urban park in Northeast China [46]. An increase in blood pressure results in higher stress relief through the up-regulating sympathetic nerve activity, salivary cortisol level, prefrontal-cortex cerebral blood flow, and parasympathetic nerve activity $[18,23,49]$. It is reasonable that people would express negative emotional expressions when they encounter an uncomfortable temperature.

\subsection{The Relationship between Facial Expressions and the Distance from Downtown}

Our studies revealed that visitors in the urban forest parks near the city center generally expressed more negative emotion and tended to show higher disgusted expressions. Our results concur with findings from the comparison between the experiences in the forest and in the urban environment $[4,14,16-18]$. Studies using the POMS method reported that after walking in the urban 
environment participants experienced artificial [14,16-18], arousal [14], and wakefulness [16-18] instead of the neutral observation. Our study identified these outcomes by facial expression analysis, which was more precise and objective to describe temporary emotional perception than the questionnaire methodology.

In detail, visitors to urban forest parks in Changchun showed less angry emotions in the rural region than downtown, while visitors in Shenyang expressed decreased sad, angry, and scared emotions with the increase of distance from downtown. In Harbin, the regression indicated a positive relationship between distance and scared expression score. This was because the urban-rural gradient therein only occupied a short distance to downtown from $1.8 \mathrm{~km}$ to $7 \mathrm{~km}$ and this distance range was indicated to have a negative effect on the positive emotion by the Poisson model. In Shenyang, because both positive and negative emotional expressions declined with the increase of distance from downtown, the Poisson model indicated no trend of contribution of this city on PRI.

Our results also indicated that when an urban forest park is located about $10 \mathrm{~km}$ away from downtown, the distance-factor is unlikely to have any effect on visitors' facial expressions. Local people believed this distance was too far away from downtown because the cost of traveling to the remote rural forest park was inevitably costly in terms of time, fuel, and patience. Outside visitors to a remote-rural forest park can hardly perceive any impact of the distance to downtown on their emotions. Some studies even reported that the city-center environment did not contribute to all-bad expereince by respondents $[8,9]$, suggesting a strong emotional response of people in urban forest parks located in the urbanized area. Therefore, an urban forest park over $10 \mathrm{~km}$ away from downtown may be not so mentally restorative as we expected, even though the park was in a highly natural environment.

\subsection{The Gender Effect on Facial Expression}

Due to the popularization of mobile devices and enhancing photographic function in cell phones, visitors have taken and increasingly uploaded much more selfies than in the past. This was one of the corollaries of social media platform development [50]. In our study, many more facial images originated from selfies by female visitors than by male visitors. This was attributed to the nature of attitude and motivational differences between male and female respondents [50]. The Poisson regression model indicated that male visitors generally showed neutral emotion in their selfies, while female visitors showed a positive contribution to the expressional emotion. Thus, the facial expressions findings suggest female visitors were able to obtain significant anxiety relaxation from the exposure to urban forest parks, but male visitors' expression was not sensitive to the urban forest experience. Our results concur with those in a recent study where female visitors reported more relief from tension and anxious mood than male visitors after a forest walk in winter [48]. By the general social characteristics of men and women, male visitors may experience more stress than female visitors, which resulted in the tendency of less happy expressions on their faces though they were standing in the restorative setting. Male visitors tended to show a natural expression on their faces, which were less likely to be posed than females [50]. In addition, a restorative forest effect was characterized by groups of trees by Jiang et al., who found that men can perceive discomfort in response to heavy tree density while women do not realize this stress [51]. Thus, tree density in urban forest parks of China might be greater than a male prefers $[8,46,47]$. However, the current understanding about the restorative response and gender difference to the forest experience is still limited. More studies are needed to detect the mechanism for the variation of emotional difference of men and women in a forest park.

\subsection{The Limitations of the Current Study}

Our study focused on the facial expressions of visitors in urban forest parks located at varying distances to the center of three cities. This methodology enabled us to compare the difference of facial expressions between forests at urban and rural areas. The urban-rural comparison can reflect the environmental and anthropogenic changes caused by urbanization $[52,53]$. However, in studies on emotional perception in response to nature experience, the urban environment was usually taken as 
the reference (or the control) to quantify participants' performance in a forest $[7,9,19]$. Therefore, our results were not designed to reveal the restorative effect of an urban forest park as we did not compare our results with those collected from the urban environment. However, our study can satisfactorily answer the question about the effect of green space in varying distances on facial expressions.

People intend to smile when taking selfies, which impacted our results' precision. This can cause some subjective bias on facial expression analysis in our study. For example, several images in our study showed the face of an intentional smile. However, this "interruption" likely existed for all images, generating a natural error in all forest parks. Another mechanical error can be generated from the number of visitors to urban forest parks, which was not evenly spread across the nine parks. Fewer photos in the suburban park of Changchun occurred because visitors to the suburban park of Changchun tended not to take selfies in front of their face and many selfies were over-decorated, which causes mechanical reading issues. This point should be considered as an interruption and should be controlled in future works.

Furthermore, we did not incorporate the factor of visitors' ages into the analysis because technically we cannot. Although photos are generally open to public without special limits by the uploader, their age belongs to the kind of personal information that most users would like to hide or omit. In addition, the FireFace software has not obtained the function to analyze both facial expressions and extra ages from the same photo of a person's face. More modern techniques or other similar software may cope with this bug in our study.

Finally, the Sina Micro-Blog permits users to keep their personal details protected, which means that their information cannot be browsed by strangers. Hence, in our study we were unable to obtain more data to study the effect of gender on facial expression. Future work is suggested to be conducted in an off-line face-to-face experiment wherein more personal details of every participant can be known.

\section{Conclusions}

In this study, 935 facial images of visitors to urban forests in three cities of Northeast China were screened and downloaded from the Sina Micro-Blog platform for facial recognition by FireFace. Eight facial expressions were recognized to quantify neutral, happy, sad, angry, surprised, scared, disgusted, and contempt scores. Factors of city-variation distance to downtown, and visitors' gender had significant effects on facial-expression scores. Visitors in urban forests at the most northern city showed fewer negative expressions than those at the more southern city. Visitors' negative expression tended to be alleviated with the increase of the urban-forest's distance to downtown within the range of no more than $10 \mathrm{~km}$. Female visitors tended to show positive emotion in their selfies, but male visitors showed no effect of facial expression on their faces. Therefore, a forest park in the rural area no longer than $10 \mathrm{~km}$ from the downtown of a northern city for a female visitor gave the most positive emotion. This study is just a case to use SNS data about facial-expression scores from visitors to forests along the urbanization gradient. Results can be used for regional urban forest evaluation and green space planning. The use of SNS photos can be extended to unlimited edges of forested lands that people are allowed to visit. The data about facial expressions can also be used as a dependent variable to detect their correlates with all municipal dimensions in addition to urban forest location and distance to downtown.

Author Contributions: Conceptualization, H.W. and X.H.; methodology, H.W.; software, X.C.; formal analysis, X.C.; investigation, X.C. and H.W.; writing—original draft preparation, H.W.; writing—review and editing, R.J.H. and X.H.; visualization, H.W.; project administration, X.H.; funding acquisition, X.H.

Funding: This research was funded by the Strategic Priority Research Program of the Chinese Academy of Sciences (grant number XDA23070503), National Natural Science Foundation of China (grant number 41971122; 41861017; 31600496), the National Key Research and Development Program of China (grant number 2016YFC0500300), the Regional Key Project in S\&T Services Network Program of Chinese Academy of Sciences (grant number KFJ-STS-QYZD-044; KFJ-STS-ZDTP-048), and the Funding for Jilin Environmental Science (grant number 2017-16).

Acknowledgments: Authors acknowledge Haoming Guan for the assistance of data collection and figure generation. 
Conflicts of Interest: The authors declare no conflict of interest.

\section{References}

1. Chen, W.; Jim, C.Y. Resident motivations and willingness-to-pay for urban biodiversity conservation in guangzhou (china). Environ. Manag. 2010, 45, 1052-1064. [CrossRef] [PubMed]

2. Morita, E.; Fukuda, S.; Nagano, J.; Hamajima, N.; Yamamoto, H.; Iwai, Y.; Nakashima, T.; Ohira, H.; Shirakawa, T. Psychological effects of forest environments on healthy adults: Shinrin-yoku (forest-air bathing, walking) as a possible method of stress reduction. Public Health 2007, 121, 54-63. [CrossRef] [PubMed]

3. Kim, W.; Lim, S.K.; Chung, E.J.; Woo, J.M. The effect of cognitive behavior therapy-based psychotherapy applied in a forest environment an physiological changes and remission of major depressive disorder. Psychiatry Investig. 2009, 6, 245-254. [CrossRef] [PubMed]

4. Park, B.J.; Furuya, K.; Kasetani, T.; Takayama, N.; Kagawa, T.; Miyazaki, Y. Relationship between psychological responses and physical environments in forest settings. Landsc. Urban. Plan. 2011, 102, 24-32. [CrossRef]

5. Ochiai, H.; Ikei, H.; Song, C.R.; Kobayashi, M.; Miura, T.; Kagawa, T.; Li, Q.; Kumeda, S.; Imai, M.; Miyazaki, Y. Physiological and psychological effects of a forest therapy program on middle-aged females. Int. J. Environ. Res. Public Health 2015, 12, 15222-15232. [CrossRef] [PubMed]

6. Song, C.R.; Ikei, H.; Miyazaki, Y. Physiological effects of nature therapy: A review of the research in Japan. Int. J. Environ. Res. Public Health 2016, 13, 781. [CrossRef]

7. Chun, M.H.; Chang, M.C.; Lee, S.J. The effects of forest therapy on depression and anxiety in patients with chronic stroke. Int. J. Neurosci. 2017, 127, 199-203. [CrossRef]

8. Guan, H.; Wei, H.; He, X.; Ren, Z.; An, B. The tree-species-specific effect of forest bathing on perceived anxiety alleviation of young-adults in urban forests. Ann. For. Res. 2017, 60, 327-341. [CrossRef]

9. Stigsdotter, U.K.; Corazon, S.S.; Sidenius, U.; Kristiansen, J.; Grahn, P. It is not all bad for the grey city - a crossover study on physiological and psychological restoration in a forest and an urban environment. Health Place 2017, 46, 145-154. [CrossRef]

10. Li, Q.; Morimoto, K.; Nakadai, A.; Inagaki, H.; Katsumata, M.; Shimizu, T.; Hirata, Y.; Hirata, K.; Suzuki, H.; Miyazaki, Y.; et al. Forest bathing enhances human natural killer activity and expression of anti-cancer proteins. Int. J. Immunopathol. Pharmacol. 2007, 20, 3-8. [CrossRef]

11. Lee, J.; Park, B.J.; Tsunetsugu, Y.; Kagawa, T.; Miyazaki, Y. Restorative effects of viewing real forest landscapes, based on a comparison with urban landscapes. Scand. J. Forest Res. 2009, 24, 227-234. [CrossRef]

12. Park, B.-J.; Tsunetsugu, Y.; Kasetani, T.; Hirano, H.; Kagawa, T.; Sato, M.; Miyazaki, Y. Physiological effects of shinrin-yoku (taking in the atmosphere of the forest) -Using salivary cortisol and cerebral activity as indicators. J. Physiol. Anthropol. 2007, 26, 123-128. [CrossRef] [PubMed]

13. Park, B.J.; Tsunetsugu, Y.; Kasetani, T.; Morikawa, T.; Kagawa, T.; Miyazaki, Y. Physiological effects of forest recreation in a young conifer forest in hinokage town, Japan. Silva Fenn. 2009, 43, 291-301. [CrossRef]

14. Lee, J.; Tsunetsugu, Y.; Takayama, N.; Park, B.J.; Li, Q.; Song, C.R.; Komatsu, M.; Ikei, H.; Tyrvainen, L.; Kagawa, T.; et al. Influence of forest therapy on cardiovascular relaxation in young adults. Evid. Complement. Altern. Med. 2014, 2014, 7. [CrossRef]

15. Sung, J.; Woo, J.M.; Kim, W.; Lim, S.K.; Chung, E.J. The effect of cognitive behavior therapy-based forest therapy program on blood pressure, salivary cortisol level, and quality of life in elderly hypertensive patients. Clin. Exp. Hypertens. 2012, 34, 1-7. [CrossRef]

16. Song, C.R.; Joung, D.W.; Ikei, H.; Igarashi, M.; Aga, M.; Park, B.J.; Miwa, M.; Takagaki, M.; Miyazaki, Y. Physiological and psychological effects of walking on young males in urban parks in winter. J. Physiol. Anthropol. 2013, 32, 5. [CrossRef]

17. Song, C.; Ikei, H.; Igarashi, M.; Miwa, M.; Takagaki, M.; Miyazaki, Y. Physiological and psychological responses of young males during spring-time walks in urban parks. J. Physiol. Anthropol. 2014, $33,7$. [CrossRef]

18. Song, C.R.; Ikei, H.; Kobayashi, M.; Miura, T.; Taue, M.; Kagawa, T.; Li, Q.; Kumeda, S.; Imai, M.; Miyazaki, Y. Effect of forest walking on autonomic nervous system activity in middle-aged hypertensive individuals: A pilot study. Int. J. Environ. Res. Public Health 2015, 12, 2687-2699. [CrossRef]

19. Bratman, G.N.; Hamilton, J.P.; Hahn, K.S.; Daily, G.C.; Gross, J.J. Nature experience reduces rumination and subgenual prefrontal cortex activation. Proc. Natl. Acad. Sci. USA 2015, 112, 8567-8572. [CrossRef] 
20. Sonntag-Ostrom, E.; Stenlund, T.; Nordin, M.; Lundell, Y.; Ahlgren, C.; Fjellman-Wiklund, A.; Jarvholm, L.S.; Dolling, A. Nature's effect on my mind-patients' qualitative experiences of a forest-based rehabilitation programme. Urban. For. Urban. Green. 2015, 14, 607-614. [CrossRef]

21. United Nations. Department of Economic and Social Affairs, Population Division, World Urbanization Prospects: The 2011 Revision; United Nations: New York, NY, USA, 2012; pp. 1-4.

22. Choudhury, S.; Pradhan, M.P.; Sharma, P.; Kar, S.K. Determining Urban Emotion Using an Unsupervised Learning Approach: A Case Study around Majitar, East District, Sikkim. In Proceedings of the 2016 International Conference on Energy Efficient Technologies for Sustainability, TamilNadu, India, 7-8 April 2016; IEEE: Piscataway, NY, USA; pp. 134-141.

23. Li, Q.; Kobayashi, M.; Kumeda, S.; Ochiai, T.; Miura, T.; Kagawa, T.; Imai, M.; Wang, Z.Y.; Otsuka, T.; Kawada, T. Effects of forest bathing on cardiovascular and metabolic parameters in middle-aged males. Evid. Complement. Altern. Med. 2016, 2016. [CrossRef] [PubMed]

24. Bielinis, E.; Lukowski, A.; Omelan, A.; Boiko, S.; Takayama, N.; Grebner, D. The effect of recreation in a snow-covered forest environment on the psychological wellbeing of young adults: Randomized controlled study. Forests 2019, 10, 827. [CrossRef]

25. Bielinis, E.; Bielinis, L.; Krupinska-Szeluga, S.; Lukowski, A.; Takayama, N. The effects of a short forest recreation program on physiological and psychological relaxation in young polish adults. Forests 2019, 10, 34. [CrossRef]

26. Casado-Arzuaga, I.; Madariaga, I.; Onaindia, M. Perception, demand and user contribution to ecosystem services in the bilbao metropolitan greenbelt. J. Environ. Manag. 2013, 129, 33-43. [CrossRef]

27. Dou, Y.H.; Zhen, L.; De Groot, R.; Du, B.Z.; Yu, X.B. Assessing the importance of cultural ecosystem services in urban areas of beijing municipality. Ecosyst. Serv. 2017, 24, 79-90. [CrossRef]

28. Carvalho-Ribeiro, S.M.; Lovett, A. Is an attractive forest also considered well managed? Public preferences for forest cover and stand structure across a rural/urban gradient in northern portugal. Forest Policy Econ. 2011, 13, 46-54. [CrossRef]

29. Erol, S.Y. Differences between urban and rural population with respect to demand on forestry aspects, in a case study of the turkish province of balikesir. Cienc. Rural 2012, 42, 436-443. [CrossRef]

30. Mukherjee, D.; Safraj, S.; Tayyab, M.; Shivashankar, R.; Patel, S.A.; Narayanan, G.; Ajay, V.S.; Ali, M.K.; Narayan, K.M.V.; Tandon, N.; et al. Park availability and major depression in individuals with chronic conditions: Is there an association in urban india? Health Place 2017, 47, 54-62. [CrossRef]

31. McNair, D.M.; Heuchert, J.P. Profile of Mood State. Technical Update; Multi-Health Systems Inc.: North Tonawanda, NY, USA, 2013; pp. 1-4.

32. Hsu, H.H.; Chen, Y.F.; Lin, C.Y.; Hsieh, C.W.; Shih, T.K. Emotion attention to friends on social networking services. J. Int. Technol. 2012, 13, 963-970.

33. Sanadhya, S.; Singh, S. Trust calculation with ant colony optimization in online social networks. In Proceedings of the Eleventh International Multi-Conference on Information Processing-2015 (IMCIP-2015), Bangalore, India, 21-23 August 2015; Shenoy, P.D., Lyengar, S.S., Raja, K.B., Venugopal, K.R., Buyya, R., Patnaik, L.M.E., Eds.; Elsevier Science Press: Amsterdam, The Netherlands, 2015; pp. 186-195.

34. Nakashima, Y.; Koyama, T.; Yokoya, N.; Babaguchi, N. Facial expression preserving privacy protection using image melding. In Proceedings of the 2015 IEEE International Conference on Multimedia \& Expo, Torino, Italy, 29 June-3 July 2015; The IEEE Press: Piscataway, NY, USA, 2015; pp. 13-29.

35. D'Ambrosio, S.; de Pasquale, S.; Iannone, G.; Malandrino, D.; Negro, A.; Patimo, G.; Scarano, V.; Spinelli, R.; Zaccagnino, R. Privacy as a proxy for green web browsing: Methodology and experimentation. Comput. Netw. 2017, 126, 81-99. [CrossRef]

36. Kerrihard, A.L.; Khair, M.B.; Blumberg, R.; Feldman, C.H.; Wunderlich, S.M. The effects of acclimation to the united states and other demographic factors on responses to salt levels in foods: An examination utilizing face reader technology. Appetite 2017, 116, 315-322. [CrossRef] [PubMed]

37. Tencent. Products \& Services. Available online: https://www.tencent.com/en-us/system.html (accessed on 25 October 2019).

38. Gu, Z.H.; Zhang, Y.; Chen, Y.; Chang, X.M. Analysis of attraction features of tourism destinations in a mega-city based on check-in data mininga case study of shenzhen, china. ISPRS Int. Geo Inf. 2016, 5, 13. 
39. Dai, L.L.; Xue, T.; Wu, B.H.; Rong, X.; Xu, B.X. Spatiotemporal structure features of network check-in activities of urban residents and their impacting factors: A case study in six urban districts of beijing. J. Asian Archit. Build. Eng. 2017, 16, 131-138. [CrossRef]

40. Xu, S.; Xu, W.D.; Chen, W.; He, X.Y.; Huang, Y.Q.; Wen, H. Leaf phenological characters of main tree species in urban forest of shenyang. PLoS ONE 2014, 9, 9. [CrossRef] [PubMed]

41. Guan, W.Q.; Gao, H.Y.; Yang, M.M.; Li, Y.; Ma, H.X.; Qian, W.N.; Cao, Z.G.; Yang, X.G. Analyzing user behavior of the micro-blogging website sina weibo during hot social events. Physica A 2014, 395, 340-351. [CrossRef]

42. Kang, M.J.; Lee, J.K.; Kang, J.W. Combining random forest with multi-block local binary pattern feature selection for multiclass head pose estimation. PLoS ONE 2017, 12, 24. [CrossRef]

43. Ngo, A.C.L.; See, J.; Phan, R.C.W. Sparsity in dynamics of spontaneous subtle emotions: Analysis and application. IEEE Trans. Affect. Comput. 2017, 8, 396-411. [CrossRef]

44. Danner, L.; Sidorkina, L.; Joechl, M.; Duerrschmid, K. Make a face! Implicit and explicit measurement of facial expressions elicited by orange juices using face reading technology. Food. Qual. Prefer. 2014, 32, 167-172. [CrossRef]

45. Conover, W.J.; Ronald, L.I. Rank transformations as a bridge between parametric and nonparametric statistics. Am. Stat. 1981, 35, 124-129.

46. An, B.Y.; Wang, D.; Liu, X.J.; Guan, H.M.; Wei, H.X.; Ren, Z.B. The effect of environmental factors in urban forests on blood pressure and heart rate in university students. J. For. Res. 2019, 24, 27-34. [CrossRef]

47. Zhou, C.W.; Yan, L.B.; Yu, L.F.; Wei, H.X.; Guan, H.M.; Shang, C.F.; Chen, F.Y.; Bao, J.Z. Effect of short-term forest bathing in urban parks on perceived anxiety of young-adults: A pilot study in guiyang, southwest china. Chin. Geogr. Sci. 2019, 29, 139-150. [CrossRef]

48. Bielinis, E.; Takayama, N.; Boiko, S.; Omelan, A.; Bielinis, L. The effect of winter forest bathing on psychological relaxation of young polish adults. Urban. For. Urban. Green. 2018, 29, 276-283. [CrossRef]

49. Yu, C.P.; Lin, C.M.; Tsai, M.J.; Tsai, Y.C.; Chen, C.Y. Effects of short forest bathing program on autonomic nervous system activity and mood states in middle-aged and elderly individuals. Int. J. Environ. Res. Public Health 2017, 14, 897. [CrossRef] [PubMed]

50. Shah, R.; Tewari, R. Demystifying 'selfie': A rampant social media activity. Behav. Inf. Technol. 2016, 35, 864-871. [CrossRef]

51. Jiang, B.; Chang, C.Y.; Sullivan, W.C. A dose of nature: Tree cover, stress reduction, and gender differences. Landsc. Urban. Plan. 2014, 132, 26-36. [CrossRef]

52. Lv, H.L.; Wang, W.J.; He, X.Y.; Xiao, L.; Zhou, W.; Zhang, B. Quantifying tree and soil carbon stocks in a temperate urban forest in northeast china. Forests 2016, 7, 200. [CrossRef]

53. Zhai, C.; Wang, W.J.; He, X.Y.; Zhou, W.; Xiao, L.; Zhang, B. Urbanization drives soc accumulation, its temperature stability and turnover in forests, northeastern china. Forests 2017, 8, 130. [CrossRef] 